\title{
Editorial I
}

\section{Adult Swallowing Disorders: Focus on Quality of Life}

\author{
Geraldo Pereira Jotz ${ }^{1,2}$ (1) \\ 1 Department of Morphological Sciences, Universidade Federal do Rio \\ Grande do Sul, Porto Alegre, RS, Brazil \\ 2 Health Sciences Postgraduate Course, Universidade Federal de \\ Ciências da Saúde de Porto Alegre, Porto Alegre, RS, Brazil
}

Int Arch Otorhinolaryngol 2019;23:e371-e372.

Annually, millions of individuals develop dysphagia worldwide. Dysphagia is not a disease in itself, but a component of the group of signs and/or symptoms of an underlying disease. The disease course of patients with dysphagia differs from the diagnosis up to the treatment, when the gastrointestinal tract is assessed down to the stomach. The use of a multidisciplinary approach has been a great advancement in the management of patients with dysphagia, providing better assessments and treatments, especially regarding quality of life. ${ }^{1}$

In 1993, when we were studying the laryngeal aspects of gastroesophageal reflux disease, we tried to develop a diet that was "pleasant" to patients with dysphagia, and that did not pose difficulties to swallowing, as a part of the clinical treatment. ${ }^{2}$ Among other professionals in the multidisciplinary team, speech therapists played a key role, contributing significantly to the treatment of patients with dysphagia ${ }^{1,3,4}$, with focus on their quality of life.

Two decades ago, the approach of medical professionals for patients with swallowing disorders was completely different from the current one, and their concern was to maintain a "food route," regardless of the quality of life of the patient.

Over the years, swallowing disorders have become increasingly prevalent because the population is aging. However, publications have reported only a few advances with respect to the rehabilitation of patients with dysphagia, perhaps because of the various causes of dysphagia, such as degenerative diseases, in which the treatment has two objectives: dysphagia and the underlying disease. Through regenerative medicine, we have achieved several advances in the treatment of numerous diseases, but it has not positively reflected in the treatment of patients with dysphagia, due to multifactorial causes. ${ }^{1,3}$ However, both swallowing and speech play fundamental roles in daily life. The complications of dysphagia may worsen, regardless of the individuals' socioeconomic or demographic factors. Recognition of this condition is a fundamental prognostic factor for immediate worsening of the patients' status and possible rapid progression to death. ${ }^{1,3,4}$

The literature shows that between $45 \%$ and $65 \%$ of the patients with a cerebrovascular accident (CVA) have swallowing difficulties in the first 6 months following the event. Although many of these patients regain adequate swallowing, aspiration persists in approximately $50 \%$ of them, and approximately $25 \%$ of them may die of aspiration pneumonia within 1 year of the CVA. ${ }^{1,5}$

Parkinson disease has been increasing in prevalence because of population aging, and is commonly associated with speech and swallowing disorders. Approximately $50 \%$ of the patients with Parkinson disease develop dysphagia within 5 years of the onset of symptoms. Dysphagia is also widespread among people with Alzheimer disease, but the mechanism is unclear. ${ }^{1,5}$

A study ${ }^{6}$ evaluating 189 patients aged 14 to 55 years with mental disability, published in the International Archives of Otorhinolaryngology in 2019, showed no significant effects of gender or mental disability on the aggravation of dysphagia. ${ }^{6}$

In patients with cancer of the head or neck region, swallowing disorders are common, either caused by the involvement of the disease with the oral cavity, pharynx, and/or larynx, or caused by the treatment involving irradiation of the tissues or broad resections of the oral cavity, pharynx, and/or esophagus, with or without reconstruction of the neighboring or distant tissues. ${ }^{1}$

Swallowing disorders have a major impact on public health to a large extent because of the nutritional aspect, and they may lead to weight loss. Several medications can cause swallowing disorders as an adverse effect. Studies in the literature are increasingly correlating the impact of dysphagia on the patients' quality of life. ${ }^{1,2}$

Aging causes changes in muscle composition by degenerating the components of the motor unit and its coordination, changing its shape, decreasing the fast-twitch fibers, and
Address for correspondence Prof. Geraldo Pereira Jotz, MD, PhD, Departmento de Ciências Morfológicas, Universidade Federal do Rio Grande do Sul, Avenida Paulo Gama 110-Farroupilha, Porto Alegre, RS, 90040-060, Brazil (e-mail: iaorl@iaorl.org).
DOI https://doi.org/ 10.1055/s-0039-1700503. ISSN 1809-9777.
Copyright @ 2019 by Thieme Revinter Publicações Ltda, Rio de Janeiro, Brazil
License terms

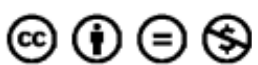


reducing the enzymes that are necessary for muscle contraction. ${ }^{1,2}$ Consequently, there are changes in the strength and mobility of the articulatory organs due to the decreased salivation, delayed chewing and swallowing processes, changes in food consistency, volume and speed at which food is ingested, and presence of oral stasis in piriform sinuses due to delayed or non-coordination in transition of the feeding bolus. ${ }^{1,2}$ Due to aging, some physiological changes occur in the mouths of the elderly, such as loss of taste sensations, leading to an increase in sugar and salt consumption, and increasing the importance of the participation of nutritionists in this rehabilitation process. ${ }^{1,3}$

An experimental study ${ }^{7}$ on salt intake and mineral loss published in this journal (2019) reported that mineral loss caused by salt intake did not directly affect the quality of bone healing after analyzing the influence of diet on osseointegration of dental implants in the elderly rats. Even with the lowest bone mineral density, the authors concluded that mineral loss did not interfere with osteointegration immediately after aging. ${ }^{7}$

Awareness regarding dysphagia is increasing, with increased focus on assisting specialists who evaluate and provide instructions for the best practices. ${ }^{1,4}$ Health professionals caring for patients with dysphagia should balance safety and efficiency, seeking to meet the patients' needs and especially their quality of life in compliance with ethics. ${ }^{3,4}$ The patient-centered approach should be based on careful and non-judgmental dialogue with patients and their family members, seeking results closer to the patients' reality, due to their comorbidities. ${ }^{1}$

Notably, financial investment is another factor affecting the morbidity and mortality of patients with dysphagia, and it is affecting health systems and individuals worldwide. Studies showed that dysphagia has increased the healthcare costs by $40 \%{ }^{3}$ The literature reveals that dysphagia has a significant impact on the physical, psychological, social, and financial aspects of the lives individuals, directly affecting their quality of life. ${ }^{3}$

In conclusion, dysphagia is associated with many diseases and with aging. Increasing research on the physiology and pathophysiology of swallowing and of structures comprising the digestive tract, coupled with constant advancements in the management of patients with dysphagia, sheds light on a promising future in terms of better quality of life for patients with dysphagia.

\section{Conflict of Interests}

The author has none to declare.

\section{References}

1 Jotz GP, Carrara-de-Angelis E. Disfagia: abordagem clínica e cirúrgica: criança, adulto e idoso. Rio de Janeiro: Elsevier; 2017

2 Jotz GP, Carrara-de-Angelis E, Barros APB. Tratado da deglutição e disfagia: no adulto e na criança. Rio de Janeiro: Revinter; 2009

3 McGinnis CM, Homan K, Solomon M, et al. Dysphagia: Interprofessional Management, Impact, and Patient-Centered Care. Nutr Clin Pract 2019;34(01):80-95. Doi: 10.1002/ncp.10239

4 Shaker R. Special Section on DRS 25th Anniversary. Dysphagia 2017;32(01):1-2. Doi: 10.1007/s00455-016-9777-8

5 Jotz GP. Dysphagia: a symptom to be controlled. Int Arch Otorhinolaryngol 2014;18(02):90-91. Doi: 10.1055/s-0034-1372694

6 Pirana S, Oliveira M, Pissini F, Andrade R. Swallowing in Patients with Mental Disability - Analysis of 189 Swallowing Video Endoscopies. Int Arch Otorhinolaryngol 2019;23(01):25-30. Doi: 10.1055/s-0038-1660775

7 Baldisserotto J, Padilha DMP, Amenábar JM. The Influence of Dietary Salt on the Osseointegration of Implants in Aging Rats. Int Arch Otorhinolaryngol 2019;23(04):427-432. Doi: 10.1055/s0039-1693141 